\title{
Evaluación de un e-portafolio de recursos pedagógicos para el desarrollo de competencias históricas. Estudio de caso
}

\author{
Evaluation of an e-portfolio of pedagogical \\ resources for the development of historical competencies. Case study \\ Humberto Andrés Álvarez Sepúlveda \\ Universidad Católica de la Santísima Concepción, Chile.凶 halvarez@ucsc.cl \\ [orcid.org/0000-0001-5729-3404]
}

\section{RESUMEN}

En este artículo se evalúa, a través de un e-portafolio, los conocimientos aplicados por un grupo de profesores en formación para diseñar una propuesta pedagógica, que ayude a sus futuros estudiantes a desarrollar los aprendizajes de segundo orden del pensamiento histórico, tales como la empatía histórica, la dimensión ética, el tiempo histórico, entre otros. Es una investigación exploratoria basada en un estudio de casos y en un diseño transeccional. Los resultados obtenidos revelan el gran desconocimiento inicial que los futuros docentes tenían acerca del alcance y la pertinencia de considerar los fundamentos epistémicos, pedagógicos y cognitivos de la historia y su didáctica a la hora de planificar actividades e instrumentos evaluativos que contribuyan a la formación del pensamiento histórico; sin embargo, las evidencias adjuntas en el e-portafolio constatan que, a lo largo del proceso formativo, fueron capaces de comprender tales principios en la construcción de los recursos enunciados.

PALABRAS CLAVE: Formación docente, pandemia Covid-19, e-portafolio, evaluación, pensamiento histórico.

\section{ABSTRACT}

This article evaluates, through an e-portfolio, the knowledge applied by a group of teachers in training to design a pedagogical proposal, which helps their future students to develop the second order learning of historical thought, such as historical empathy, ethical dimension, historical time, among others. It is an exploratory research based on a study of cases and a transectional design. The results obtained reveal the great initial lack 
of knowledge that future teachers had about the scope and relevance of considering the epistemic, pedagogical and cognitive foundations of history and its didactics when planning activities and evaluation instruments that contribute to the formation of historical thought; however, the evidence attached to the e-portfolio confirms that, throughout the training process, they were able to understand such principles in the construction of the resources mentioned.

KEY WORDS: Teacher training, Covid-19 pandemic, e-portfolio, evaluation, historical thinking.

\section{INTRODUCCIÓN}

La formación del profesorado de historia es una actividad planificada con la mayor coherencia posible, pues, en un contexto de normalidad nacional e internacional, tiene como finalidad preparar al alumnado con el conocimiento pedagógico y disciplinar suficiente para diseñar, implementar y evaluar procesos de enseñanza-aprendizaje, reflexionar sobre sus prácticas y proponer innovaciones en el ámbito educativo (Gómez et al. 2017; González et al. 2020). No obstante, en el contexto de la actual pandemia de Covid-19, este objetivo se ha visto enfrentado a una constante incertidumbre política, económica y social, ya que ha obligado a las autoridades educativas a suspender las clases presenciales, provocando que la totalidad de las universidades implementaran, de forma casi inmediata, un sistema de docencia online.

Sin embargo, no puede pretenderse que dicha acción, urgente y sobrevenida, sea análoga en experiencia, planificación y desarrollo a las propuestas que están específicamente diseñadas desde su concepción para impartirse en modalidad online (García et al. 2020). Por tal motivo, en el actual escenario pandémico, los académicos formadores han tenido que desarrollar una respuesta de emergencia para readecuar sus clases y repensar el sentido formativo de la disciplina histórica, la cual ya no tiene como propósito el dominio de aprendizajes de primer orden como fechas, personajes y acontecimientos, sino que busca el desarrollo del pensamiento histórico en los alumnos y las alumnas. Este nuevo objetivo de la especialidad busca formar a las próximas generaciones como ciudadanos(as) capaces de enfrentarse al cambio y a la incertidumbre, que imponen las constantes crisis del proceso globalizador a las sociedades presentes (Álvarez, 2020b; Van Boxtel et al. 2020; Marolla \& Saavedra, 2020).

En el contexto previsto, el formador de docentes de historia ${ }^{1}$ debe tener como prioridad la utilización de instrumentos de evaluación online y el replanteamiento de sus estrategias didácticas, para ayudar a los futuros profesores a reflexionar sobre la importancia de diseñar

1 Debido al uso extendido de los términos "formador de docentes/académico formador", "profesorado en formación/futuro docente" y "estudiante/alumno", se establece la siguiente distinción: los primeros se utilizan para designar al profesor universitario que se desempeña en las carreras de Pedagogía en Historia y Geografía y de Pedagogía en Educación Básica (o sus equivalentes internacionales); los segundos suelen estar reservados para citar a los y las estudiantes de dichas carreras; y los terceros para aludir, fundamentalmente, a los alumnos y alumnas que cursan la Enseñanza Primaria y Secundaria. 
propuestas y recursos pedagógicos que permitan fomentar el pensamiento histórico. Una propuesta interesante que se podría implementar para lograr tales objetivos es el desarrollo de un e-portafolio, donde, a través del uso de las TIC, los estudiantes pueden elaborar y anexar planificaciones, actividades e instrumentos evaluativos que permitan, siguiendo a Gómez y Miralles (2015), promover y evaluar aprendizajes de segundo orden, como la empatía histórica, el análisis de fuentes, la relevancia histórica, la dimensión ética, entre otros. Con el fin de aprovechar el potencial evaluativo del e-portafolio, el presente artículo tiene como objetivo evidenciar, a través de dicho instrumento, los conocimientos aplicados por un grupo de estudiantes de Pedagogía, de una universidad chilena, para diseñar una propuesta pedagógica que ayude a sus futuros estudiantes a desarrollar competencias históricas.

\section{ALGUNAS CONSIDERACIONES PARA EVALUAR APRENDIZAJES DE SEGUNDO ORDEN DEL PENSAMIENTO HISTÓRICO}

La preparación académica de los profesores de historia tiene como objetivo desarrollar las competencias necesarias para que éstos se puedan desempeñar, de manera óptima, en su futura labor profesional. Sin embargo, en el último decenio, el propósito de este proceso formativo ha sido ampliamente cuestionado porque no ha sido capaz de formar a docentes cualificados, que sepan enseñar a las nuevas generaciones de estudiantes a combatir los prejuicios, a cuestionar la invasión de informaciones falsas y a educarse para forjar una ciudadanía responsable y crítica (Álvarez, 2020a; Garcés, 2020).

Uno de los grandes problemas de la formación docente está relacionado con la ausencia o la escasez de actividades curriculares o temáticas que permitan al alumnado abordar la importancia de otorgar un uso pedagógico a las TIC, para promover la construcción, implementación y evaluación de unidades didácticas pertinentes y coherentes con los objetivos formativos que tiene la clase de historia en el tercer milenio. Esto, siguiendo a López (2020), se evidencia en una importante falta de sistematización de reflexiones teóricas y experiencias pedagógicas, que sea capaz de fomentar una relación activa entre didáctica y tecnología.

Otro inconveniente es el predominio de la especialidad en el tratamiento de los contenidos. Al respecto, González y colaboradores (2020) sostienen que la formación de profesores de historia está centrada fundamentalmente en el componente disciplinar, ya que se tiende a relegar el saber didáctico a un segundo plano. Valdés y Turra (2017) comparten esta postura y señalan que, en el caso de Chile, la formación de docentes de historia se fundamenta en la hegemonía incontrarrestable del conocimiento histórico, el que es visto desde una perspectiva tradicional y con un marcado acento en el relato cronológico. Este problema, además de desarticular el sentido formativo de las carreras de Pedagogía, limita la capacidad del estudiantado para comprender los procesos psicológicos que se movilizan en el trabajo basado en competencias históricas.

Sin embargo, y a pesar del impacto de las problemáticas previstas, la dificultad más significativa se observa en la falta de preparación de los futuros profesores para promover y evaluar aprendizajes de segundo orden del pensamiento histórico. Como indican Gómez y Miralles (2015), la docencia actual se centra en capacitar al profesorado, para que entrene 
a sus estudiantes a responder exámenes estandarizados, que sólo evalúan la capacidad de memorización de contenidos factuales y conceptuales relacionados con la historia tradicional, relegándose habilidades como el análisis, el razonamiento o la interpretación de documentos, que son fundamentales para el aprendizaje del pensamiento histórico.

En este contexto, resulta indispensable enseñar al profesorado en formación a evaluar competencias históricas, con el fin de que puedan lograr aprendizajes significativos, pertinentes y actualizados en sus alumnos y alumnas. Este proceso debe responder necesariamente a los fundamentos epistemológicos, pedagógicos y cognitivos de la disciplina histórica y su didáctica (Tabla 1); por esta razón, es importante señalar que cuando se evalúa en historia no se trata de analizar la capacidad de acumular o memorizar aprendizajes de primer orden, como fechas, hitos y personajes, sino que se busca valorar el desarrollo de habilidades relacionadas con el pensamiento histórico.

De acuerdo a Seixas y Morton (2012), el pensamiento histórico puede definirse como el proceso creativo que realizan los historiadores para interpretar fuentes del pasado y generar sus propias narrativas históricas. Siguiendo a Gómez y colaboradores (2017), dirigir el proceso educativo del alumnado hacia la formación del pensamiento histórico exige un cambio en la enseñanza y la práctica en el aula, que conlleva también una reflexión sobre la naturaleza de la evaluación del estudiantado y las estrategias utilizadas para la misma, ya que implica trascender del proceso evaluativo sumativo al formativo.

De esta manera, la enseñanza y evaluación son dos procesos que se entrelazan e intercambian en el proceso de aprendizaje de los futuros profesores. Al respecto, Palacios y colaboradores (2020) señalan que, tanto en las actividades de aprendizaje como en los procesos de evaluación de la clase de historia, es pertinente incorporar, desarrollar y evaluar aprendizajes que vayan más allá de conocimientos declarativos de primer orden (el qué, dónde, cuándo o quién ha llevado a cabo distintas acciones en un relato cronológico), con el fin de privilegiar procedimientos y aprendizajes de segundo orden del pensamiento histórico. En el siguiente cuadro se presentan estos conceptos con sus respectivos fundamentos.

Para evaluar estas competencias en el aula universitaria es imprescindible que el profesor sea capaz de convertir una parte de las actividades didácticas en un proceso de aprendizaje por descubrimiento. Éste se puede concebir a través de un laboratorio histórico, donde el estudiante tiene la posibilidad de simular el trabajo del historiador para investigar sobre un determinado problema (Prats, 2011; Salazar et al. 2017; Álvarez, 2020b).

En el contexto previsto, cabe destacar que el laboratorio histórico involucra una serie de procedimientos, como formular hipótesis, analizar fuentes, examinar la causalidad y construir una explicación histórica. Desde la perspectiva docente, estas tareas deben repetirse y reelaborarse siempre (adaptadas en cada momento al nivel y a la preparación del alumnado), porque suponen la base para entender cómo se construye el conocimiento histórico. Así pues, a partir de esta instancia, el profesorado en formación puede concebir el diseño de actividades de aprendizaje e instrumentos evaluativos para promover y evaluar habilidades propias del pensamiento histórico en sus futuros alumnos, con la finalidad de que puedan comprender el mundo actual y forjar una ciudadanía activa, responsable e inclusiva (VanSledright, 2014; Gómez et al. 2018; Gudín \& Chávarri, 2019; Thorp \& Persson, 2020). 
Tabla 1. Aprendizajes de segundo orden del pensamiento histórico.

\begin{tabular}{ll}
\hline Concepto & Fundamentos epistémicos, pedagógicos y cognitivos que lo sostienen \\
\hline & $\begin{array}{l}\text { Este aprendizaje contribuye a comprender la historia como una ciencia hermenéutica basada } \\
\text { en el análisis de fuentes primarias y secundarias, y tiene como propósito desarrollar un } \\
\text { análisis descriptivo y heurístico de éstas. Este trabajo se operacionaliza en un laboratorio } \\
\text { histórico, a través del cual se implementan las siguientes cuatro heurísticas: }\end{array}$ \\
$\begin{array}{l}\text { Evidencia } \\
\text { histórica }\end{array}$ & - $\quad$ Heurística de origen, teniendo en cuenta de dónde proviene el documento histórico y \\
& espacial. Contextualización, con el fin de colocar el documento en su contexto temporal y \\
& - $\quad$ Lectura cerrada, para extraer la idea principal del documento.
\end{tabular}

Permite la comprensión de conceptos temporales y convenciones cronológicas para evaluar los hechos históricos en las dimensiones pasado, presente y futuro de las diferentes sociedades. Algunas de las habilidades cognitivas que moviliza el tiempo histórico son:

Tiempo - Comprender y utilizar convenciones temporales como década, siglo, milenio, antes y histórico después de Cristo, generación, entre otras.

- $\quad$ Aplicar de forma flexible y creativa las variables del tiempo histórico, como sucesión, simultaneidad, duración, etc.

- Identificar y comparar las fases del tiempo histórico, tales como períodos de auge y crisis, cambio y continuidad, entre otras.

- $\quad$ Evaluar las dimensiones pasado, presente y futuro de la experiencia histórica para comprender la complejidad y singularidad del hecho investigado.

Permite evaluar la importancia de los hechos del pasado en el presente. Algunas de las competencias cognitivas que moviliza la relevancia histórica son:

Relevancia - Seleccionar episodios y procesos que son necesarios y pertinentes de estudiar para histórica entender el presente en perspectiva histórica.

- Comparar las dimensiones pasado y presente, y formular interrogantes sobre diversas problemáticas actuales.

- $\quad$ Comprender la durabilidad, la perspectiva, la profundidad y el impacto de las consecuencias de hechos pasados en el presente.

Promueve el análisis de las creencias, los valores y las motivaciones de las sociedades pasadas Empatía y presentes. Algunas de las competencias que moviliza la empatía histórica son:

histórica

- $\quad$ Evitar el uso del presentismo en la comprensión de la problemática investigada.

- Explicar los hechos desde la perspectiva de los sujetos históricos.

Permite analizar el pasado como una dimensión que involucra diversos fenómenos y procesos donde intervienen factores multicausales y relacionales, que desencadenan consecuencias de distinta naturaleza. Algunas de las competencias que moviliza este aprendizaje son:

Causas y consecuencias

- Identificar y clasificar las causas de los fenómenos de forma descriptiva y explicativa (contenido, función, duración, etc.).

- $\quad$ Analizar e interrelacionar causas-consecuencias.

- $\quad$ Formular hipótesis y emitir razonamientos contrafácticos.

Permite emitir juicios éticos razonados sobre acciones humanas realizadas en el pasado y reconocer el contexto histórico en el que éstas operaban. Algunas de las habilidades que

Dimensión ética moviliza la dimensión ética son:

- $\quad$ Evaluar las implicaciones actuales de las injusticias del pasado.

- Valorar responsabilidades de personajes o grupos que cometieron acciones controversiales o protagonizaron hechos históricos gloriosos.

Fuente: Elaboración propia basada en la propuesta de Sáiz y Domínguez (2017). 
Para desarrollar este itinerario, es necesario que los docentes de historia posean una teoría sólida sobre el pensamiento histórico, el aprendizaje de la disciplina y la búsqueda de marcadores de progresión cognitiva. Esto, desde el punto de vista docente, implica generar una profunda capacidad reflexiva en el futuro profesorado, para que sea capaz de intencionar la creación de actividades de aprendizaje y de instrumentos que posibiliten el desarrollo y evaluación de competencias históricas en el alumnado.

\section{EL E-PORTAFOLIO COMO INSTRUMENTO DE EVALUACIÓN ONLINE}

En el actual contexto de pandemia, la evaluación online se ha posicionado como una instancia fundamental a la hora de evidenciar el progreso académico de los estudiantes (García et al. 2020; Habib et al. 2020). Esto exige al académico formador utilizar diferentes instrumentos de evaluación online para monitorear el proceso de adquisición de competencias pedagógicas y disciplinares, que ayuden a los futuros docentes a planificar actividades e instrumentos pertinentes para promover y evaluar aprendizajes de segundo orden. Al respecto, cabe destacar que el e-portafolio o portafolio electrónico se presenta como un recurso atingente para cumplir con esta finalidad, ya que, gracias a la constante evolución de las TIC, permite ahorrar esfuerzos al momento de clasificar, archivar y ordenar los materiales que se adjuntan como evidencia.

Asimismo, como sostienen Vega y Appelgren (2019), el e-portafolio permite obtener un panorama completo sobre el desarrollo académico del estudiantado en relación con las habilidades individuales, experiencias y resultados derivados de los procesos formativos. De igual forma, posibilita el establecimiento de una estrecha interacción entre el alumnado y el tutor, así como entre estudiantes y entre colegas, ya que puede promover diálogos enriquecedores, contribuir a la retroalimentación del autor del e-portafolio y crear un entorno de aprendizaje colaborativo (Díaz et al. 2012; Moreno et al. 2014; Arancibia et al. 2017).

Junto a lo anterior, es importante resaltar que el uso del e-portafolio privilegia la evaluación cualitativa por sobre la cuantitativa, pues su objetivo es llevar a cabo una evaluación auténtica vinculada con el mundo y las necesidades reales de los y las estudiantes. Siguiendo a Berlanga y Juárez (2020), la finalidad es intentar averiguar qué sabe o qué es capaz de hacer el alumno en tareas complejas, contextualizadas y prolongadas en el tiempo.

Para el docente, el e-portafolio es un espacio de reflexión crítica y propositiva, que busca facilitar el desarrollo de entornos educativos más acordes a su práctica en el aula. Para el estudiante, representa una colección de artefactos digitales que articulan sus experiencias, desempeños y aprendizajes, que dan cuenta de una construcción integradora que involucra diferentes actividades de reflexión y de autoevaluación (Cabero et al. 2012; Soria \& Carrió, 2016; Machado et al. 2017).

Cabe destacar que existen dos tipos de e-portafolios: el e-portafolio de aprendizaje y el e-portafolio docente. El primero, como señalan Soria y Carrió (2016), se presenta en contextos escolares y universitarios como una alternativa de evaluación en que profesores y alumnos, por medio de un conjunto de recursos digitales, pueden almacenar, crear, seleccionar, organizar y editar los trabajos o las evidencias de aprendizaje. Este instrumento, además de constatar 
el progreso académico, permite evaluar la capacidad reflexiva de los estudiantes sobre sus fortalezas y debilidades, ya que el e-portafolio contribuye a planificar y autorregular su proceso de aprendizaje, a través de una colección de trabajos digitalizados, que integra la tecnología para una construcción innovadora (Díaz et al. 2011; Rubio \& Galván, 2013; Rué, 2016). Así, el e-portafolio de aprendizaje constituye una práctica educativa que promueve una evaluación integral, que considera el proceso de enseñanza-aprendizaje desde el inicio hasta el final.

Por su parte, el e-portafolio docente es aquel que permite al profesorado obtener una visión íntegra sobre el desarrollo de sus competencias pedagógicas y disciplinares, pues representa una oportunidad para reflexionar detenidamente sobre la propia práctica docente (Soledispa et al. 2020). Además, siguiendo a Bozu (2012) y a Chávez (2016), se considera como una actividad con grandes posibilidades de reflexión y aprendizaje cuando se contrasta con el trabajo realizado por otros colegas, porque ofrece la posibilidad de intercambiar experiencias y de potenciar el trabajo colaborativo en torno a fines comunes.

\section{MATERIALES Y MÉTODOS}

\section{Tipo y diseño del estudio}

Es una investigación exploratoria basada en una metodología cualitativa y en un diseño transeccional. El estudio es exploratorio en cuanto se pretende dar una visión general de tipo aproximativo respecto al diseño de la propuesta pedagógica consignada en los cursos de la muestra. Es cualitativa porque respondió a la necesidad de analizar una realidad educativa compleja, que no cabe considerar en términos de cantidad, intensidad o frecuencia, sino percibirla e interpretarla desde la perspectiva de los participantes en el contexto de la experiencia (Denzin \& Lincoln, 2012; Ponce, 2013; González \& Fàbregues, 2019). El diseño es transeccional debido a que los datos de la propuesta fueron recolectados en el primer semestre de 2020.

Como estrategia metodológica se recurrió al estudio de casos (Coller, 2005; Simons, 2011), porque la investigación tiene como objetivo evaluar, en forma situada y sistemática, la información obtenida de la experiencia para cumplir con el propósito de este estudio.

\section{Contexto de la investigación}

En este estudio se consigna la elaboración de un e-portafolio de aprendizaje, que se desarrolló en el primer semestre de 2020 en un grupo de 58 estudiantes de Pedagogía de una universidad chilena. Esta muestra fue intencionada, pues la investigación requirió de alumnos y alumnas que hayan cursado asignaturas donde se impartan contenidos vinculados a la historia y su respectiva enseñabilidad. Siguiendo este criterio, cabe destacar que el e-portafolio fue utilizado en tres actividades curriculares (Tabla 3) para evidenciar, en modalidad online, los conocimientos históricos y pedagógicos aplicados por el profesorado en formación para planificar actividades e instrumentos, que permitan fomentar y evaluar habilidades históricas. Para diseñar el e-portafolio, los futuros docentes tuvieron que seguir el itinerario de trabajo señalado en la Tabla 2. 
Tabla 2. Instructivo de diseño del e-portafolio.

Diagnóstico: Delimite una problemática histórica que considere necesario replantear a través de una propuesta de innovación pedagógica. Se sugiere revisar los textos escolares, los programas de estudio y otros insumos curriculares de la Enseñanza Básica o Media para definir la temática y realizar el diagnóstico correspondiente.

Propuesta pedagógica: Elabore una propuesta pedagógica para 3 o 4 clases, que incluya curso, cantidad de estudiantes, aprendizajes esperados u objetivo de aprendizaje, objetivos de aprendizaje transversal, saberes e indicadores de evaluación. En esta planificación debe estipular el diseño de actividades e instrumentos, que permitan promover y evaluar los aprendizajes de segundo orden del pensamiento histórico en el estudiantado.

Plataforma educativa y recursos pedagógicos: Construya un e-portafolio en la plataforma de Google Sites, que incluya la propuesta pedagógica y un mínimo de 6 estrategias metodológicas y evaluativas relacionadas con el objetivo de la actividad.

Reflexión pedagógica: Desarrolle una reflexión, fundamentada de manera teórica y empírica, sobre la importancia de planificar recursos pedagógicos que permitan desarrollar y evaluar el pensamiento histórico, y las posibles limitaciones y potencialidades para su aplicación futura.

Exposición oral vía zoom: A través de una presentación online, reflexione sobre la pertinencia de su propuesta pedagógica y de sus respectivos recursos para promover el pensamiento histórico en sus futuros estudiantes.

Fuente: Elaboración propia.

\section{El temario de trabajo planificado es el siguiente:}

Tabla 3. Ejes temáticos trabajados en el e-portafolio por cada asignatura.

\begin{tabular}{llll}
\hline $\begin{array}{l}\text { Actividad } \\
\text { curricular }\end{array}$ & $\begin{array}{l}\text { Semestre de } \\
\text { la Carrera }\end{array}$ & $\begin{array}{l}\text { Cantidad de } \\
\text { alumnos }\end{array}$ & Grupos de trabajo \\
\hline & & & \\
& & & $\begin{array}{l}\text { Equipo 1: } \mathrm{P} 1+\mathrm{P} 2+\mathrm{P} 3+\mathrm{P} 4 \\
\text { Equipo 2: } \mathrm{P} 5+\mathrm{P} 6+\mathrm{P} 7+\mathrm{P} 8\end{array}$ \\
& & & Equipo 3: $\mathrm{P} 9+\mathrm{P} 10+\mathrm{P} 11+\mathrm{P} 12$ \\
Cátedra I & Tercer & 28 & Equipo 4: $\mathrm{P} 13+\mathrm{P} 14+\mathrm{P} 15+\mathrm{P} 16$ \\
& semestre & & Equipo 5: $17+\mathrm{P} 18+\mathrm{P} 19+\mathrm{P} 20$ \\
& & & Equipo 6: $\mathrm{P} 21+\mathrm{P} 22+\mathrm{P} 23+\mathrm{P} 24$ \\
& & Equipo 7: $\mathrm{P} 25+\mathrm{P} 26+\mathrm{P} 27+\mathrm{P} 28$
\end{tabular}

Temática

Controversias de temáticas ciudadanas en perspectiva histórica, como, por ejemplo: la importancia de los deberes y derechos de las personas en la sociedad actual (equipo 2); la relevancia histórica de los pueblos originarios existentes en Chile (equipo 4); y las causas y consecuencias del Estallido Social en el presente (equipo 6).

Controversias de la Historia de Chile, como, por ejemplo: la prevalencia de la doctrina del descubrimiento de Chile en el currículum (equipo 8); las

Equipo 8: P29+P30+P31+P32 Equipo 9: $\mathrm{P} 33+\mathrm{P} 34+\mathrm{P} 35+\mathrm{P} 36$

$\begin{array}{ll}\text { Cátedra II } & \begin{array}{l}\text { Séptimo } \\ \text { semestre }\end{array}\end{array}$
Equipo 10: $\mathrm{P} 37+\mathrm{P} 38+\mathrm{P} 39+\mathrm{P} 40$ Equipo 11: $\mathrm{P} 41+\mathrm{P} 42+\mathrm{P} 43+\mathrm{P} 44$ Equipo 12: $\mathrm{P} 45+\mathrm{P} 46+\mathrm{P} 47+\mathrm{P} 48$ Equipo 13: $\mathrm{P} 49+\mathrm{P} 50+\mathrm{P} 51+\mathrm{P} 52$ implicaciones de la violencia en el proceso de mestizaje (equipo 9); las características de la sociedad colonial (equipo 10); la importancia de la Guerra del Pacífico en la configuración territorial actual (equipo 11); la relevancia de la Ocupación de la Araucanía (equipo 12); y la exclusión de la mujer en la historia chilena (equipo 13). 
Continuación Tabla 3

\begin{tabular}{lllll}
\hline $\begin{array}{l}\text { Actividad } \\
\text { curricular }\end{array}$ & $\begin{array}{l}\text { Semestre de } \\
\text { la Carrera }\end{array}$ & $\begin{array}{l}\text { Cantidad de } \\
\text { alumnos }\end{array}$ & Grupos de trabajo & Temática \\
\hline & & & & $\begin{array}{l}\text { Controversias contemporáneas de } \\
\text { la Historia de Chile y del Mundo. En } \\
\text { este tópico, las temáticas trabajadas } \\
\text { fueron el rol de la mujer durante la }\end{array}$ \\
Cátedra III & $\begin{array}{l}\text { Décimo } \\
\text { semestre }\end{array}$ & 6 & $\begin{array}{l}\text { Equipo 14: P53+P54+P55 } \\
\text { Equipo 15: P56+P57+P58 }\end{array}$ & $\begin{array}{l}\text { Segunda Guerra Mundial (equipo 14) } \\
\text { yel impacto de la Dictadura Militar } \\
\text { de Augusto Pinochet en el presente } \\
\text { (equipo 15). }\end{array}$ \\
\hline
\end{tabular}

Fuente: Elaboración propia.

\section{Técnicas e instrumentos utilizados}

La amplitud y complejidad de la información requerida para cumplir con el propósito de la investigación exige pensar en una estrategia basada en una combinación de técnicas con diferente grado de interrelación, para obtener datos relevantes y conducentes a la construcción de un conocimiento más holístico y comprensivo de la problemática. En consecuencia, se realizaron una serie de observaciones de las clases, un completo análisis de diversos insumos de información y tres grupos focales que sirvieron para complementar la información obtenida.

Desde un punto de vista metodológico, las observaciones de las clases permitieron recopilar datos acerca del desempeño académico del alumnado durante el desarrollo del e-portafolio. En función del objetivo de la investigación, se realizó un tipo de observación participante para brindar un proceso de retroalimentación efectivo, que ayude a los futuros docentes a mejorar sus aprendizajes pedagógicos y disciplinares. Este tipo de observación se llevó a cabo a través de un enfoque etnográfico virtual y online (Hine, 2011; Suárez, 2020), ya que se utilizaron medios sincrónicos (aplicación zoom) y asincrónicos (foro, correo electrónico, plataforma moodle y grabaciones de clases). El instrumento diseñado para el registro de las observaciones fue el diario de campo. Su estructura, organizada en siete secciones, permitió recoger datos relativos a las limitaciones y a las potencialidades que tuvieron los y las estudiantes durante la planificación de la propuesta pedagógica.

Con el fin de complementar y contrastar la información obtenida con la observación de las sesiones, se examinaron las evidencias adjuntas por los futuros profesores en los e-portafolios, y la rúbrica analítica diseñada por el docente para evaluar dicho recurso. El instrumento utilizado para organizar los datos de dichos documentos fue una ficha conformada por un conjunto de indicadores, distribuidos en distintas dimensiones y subdimensiones, a fin de identificar, en primer lugar, los fundamentos epistémicos, pedagógicos y cognitivos de la didáctica de la historia que están presentes en el diseño de los recursos y, en segundo lugar, las formas en que son explicitadas las dinámicas de trabajo en los protocolos de las actividades elaboradas. 
La información recogida en las dos fases previas se complementó con la obtenida en tres grupos de discusión: uno en cada asignatura. Aprovechando la sinergia generada por el trabajo colaborativo desarrollado en la propuesta, los futuros profesores pudieron exponer visiones derivadas de sus experiencias personales con respecto a la elaboración del e-portafolio y a los conocimientos históricos y pedagógicos aplicados en este recurso. El uso de esta técnica resultó especialmente pertinente para comprender, como sugiere Barbour (2013), la forma en que las personas elaboran socialmente un conocimiento crítico del tema planteado. El instrumento utilizado para ordenar los datos recolectados en los grupos de discusión fue una guía en la que, además de explicitarse los objetivos de la conversación, se establecieron pautas relativas a la dinámica de trabajo y al rol de observador/moderador que, en esta instancia, asumió el docente. Asimismo, se plantearon preguntas referidas a los dos grandes focos de indagación del estudio: (1) la importancia de desarrollar el pensamiento histórico en la enseñanza de la disciplina; (2) y la pertinencia de considerar los fundamentos de la clase de historia en el diseño de actividades e instrumentos para promover y evaluar competencias históricas en el estudiantado.

Con el fin de dotar de validez y fiabilidad a los instrumentos mencionados, se les sometió a una cuidadosa revisión a través de sucesivas pruebas piloto. Entre los parámetros adoptados para asegurar la calidad de éstos, se encuentran los criterios de credibilidad, transferibilidad, dependencia y confirmabilidad propuestos por Guba y Lincoln (2012). También se utilizó la práctica de la reflexividad (Domingo \& Gómez, 2014) para evitar que las predisposiciones personales pudieran afectar el proceso de investigación y sus resultados. Se aplicó, además, el criterio de multiplicidad de voces (Moral, 2006) para otorgar un lugar preferencial en el estudio a la perspectiva de los informantes.

Para examinar los datos, se utilizó el análisis documental; por este motivo, se realizaron dos instancias de triangulación hermenéutica (Cisterna, 2005); en primera instancia, se llevó a cabo una que interrelacionaba únicamente la información suministrada por los instrumentos utilizados para la recogida de datos; y, en segunda instancia, se ejecutó una triangulación entre dichos insumos y el marco teórico, con el fin de generar nuevos procesos interpretativos y verificar posibles resultados similares (Flick, 2014).

\section{RESULTADOS Y DISCUSIÓN}

Al comienzo de la experiencia, una primera cuestión que llamó poderosamente la atención fue el gran desconocimiento de los futuros profesores sobre la pertinencia de considerar los fundamentos epistémicos, pedagógicos y cognitivos de la disciplina histórica y su enseñabilidad a la hora de diseñar estrategias metodológicas y evaluativas para promover aprendizajes de segundo orden en el alumnado.

Este problema se manifestó de dos maneras. Por una parte, se evidenció en las primeras versiones de los recursos pedagógicos elaborados por los estudiantes, ya que no incorporaban ningún elemento concreto que permitiera distinguir su pertinencia 
para fomentar o evaluar el pensamiento histórico, tales como la inclusión de actividades basadas en la empatía histórica, el desarrollo de un laboratorio histórico y sus respectivas cuatro heurísticas, o la evaluación de convenciones temporales o cronológicas. Por otra parte, también se constató en el proceso de planificación de dichos insumos, donde prevaleció el uso de modelos pedagógicos generales de corte tradicional o expositivo que no respondían a las especificidades de la asignatura de Historia, cuya situación era asumida por los alumnos y las alumnas como una cuestión normalizada dentro de su formación universitaria.

Otro tema relevante a destacar es que el estudiantado, al inicio de la actividad, tuvo varias dificultades para replantear y mejorar constantemente los recursos pedagógicos planificados y adjuntos en el e-portafolio de aprendizaje. Entre los inconvenientes observados, se encuentran la sobrecarga de trabajo que implicaba el desarrollo de la propuesta, el escaso dominio tecnológico de algunos equipos para manejar la plataforma de Google Sites, los innumerables problemas de conectividad que afectó, de forma frecuente, al trabajo grupal, y la falta de comprensión sobre los fundamentos que rigen el pensamiento histórico.

La situación prevista, en primer lugar, se debe a que es la primera experiencia que tiene el profesorado en formación con este tipo de propuesta; en segundo lugar, se explica porque la formación docente se centra exclusivamente en el conocimiento historiográfico disciplinar, lo cual coincide con los hallazgos obtenidos por Valdés y Turra (2017) y por González y colaboradores (2020). Esto último ocurre porque la didáctica de la especialidad es un área incorporada de forma reciente en la formación inicial docente y, además, se debe a que dos de los tres cursos de la muestra se basan en programas que, a pesar de contar con resultados de aprendizajes que se enmarcan en el ámbito pedagógico, tienen un claro sustento disciplinar, que se visualiza en que todas las unidades temáticas consignadas se encuadran en la historia chilena y mundial.

Como señalan Valdés y Turra (2017), todo lo anterior ha llegado a fundar una identidad eminentemente disciplinar en los sujetos que participan del proceso formativo, donde el académico formador se centra fundamentalmente en transmitir, de un modo unidireccional, una serie de saberes históricos enciclopédicos a sus alumnos y alumnas. Esto último ha contribuido a preservar el tradicionalismo academicista que todavía sigue predominando en la formación de docentes de historia (Álvarez, 2020b).

A pesar de las dificultades previstas, resulta relevante señalar que el profesorado en formación, en la medida que avanzaba en la elaboración del e-portafolio, fue capaz de ir comprendiendo las particularidades epistémicas, pedagógicas y cognitivas de la asignatura de Historia para construir, de forma pertinente y atingente, los distintos protocolos de las actividades y de los instrumentos evaluativos consignados para intencionar el desarrollo de competencias históricas.

Se adjunta, a continuación, una matriz de análisis por cada aprendizaje del pensamiento histórico para explicitar las evidencias más significativas elaboradas por el alumnado, y evaluar los conocimientos pedagógicos y disciplinares aplicados en el diseño de los recursos solicitados. 
Tabla 4. Relevancia histórica.

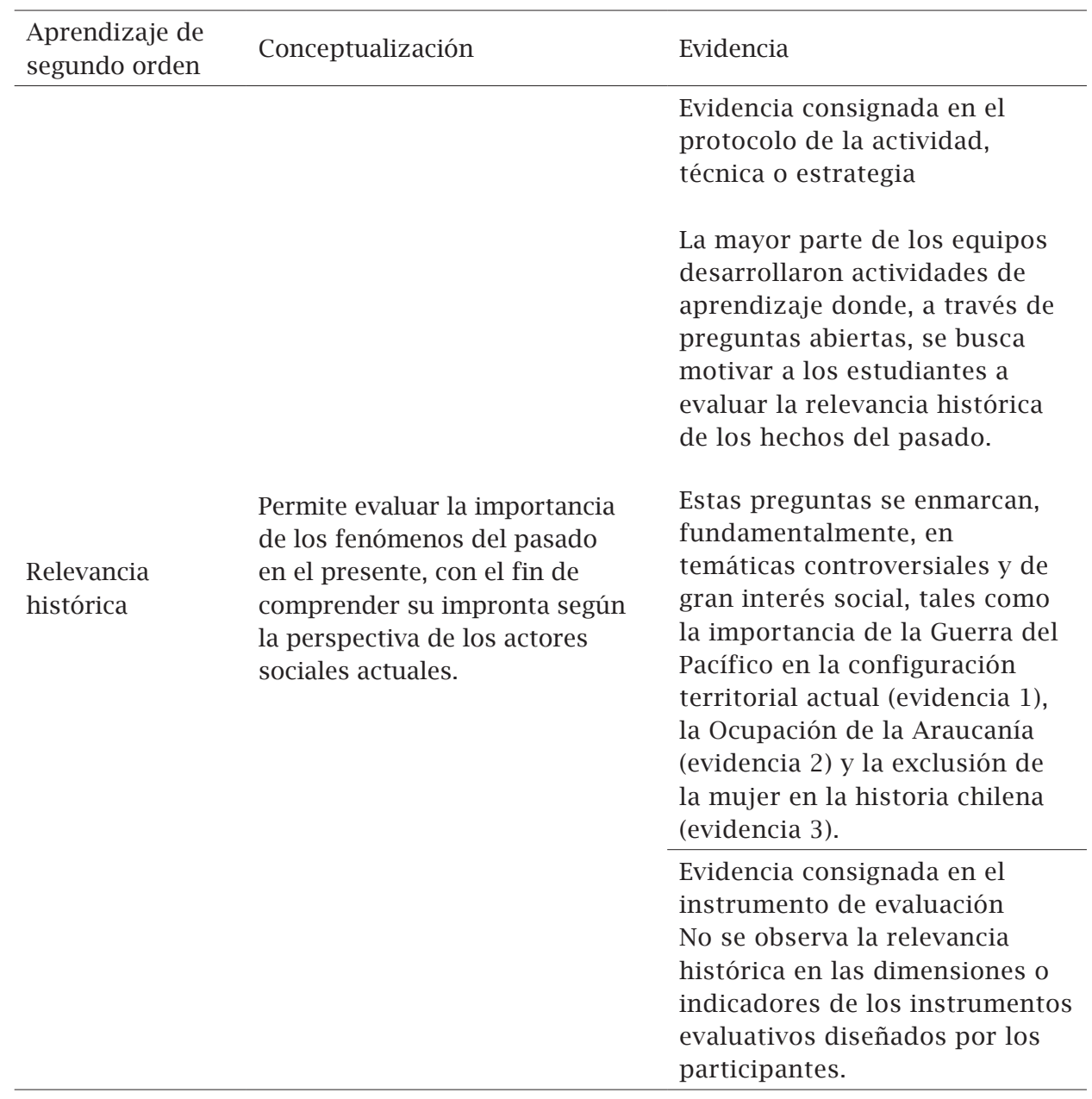

Evidencia 1 (Equipo 11): Explique la importancia de la Guerra del Pacífico para conocer la configuración actual del territorio chileno.

Evidencia 2 (Equipo 12): Evalúe la relevancia de la Ocupación de la Araucanía para comprender el actual conflicto entre el Estado y el pueblo mapuche.

Evidencia 3 (Equipo 13): ¿Crees que la invisibilización de la mujer en los textos escolares de Historia, Geografía y Ciencias Sociales contribuye a agudizar la discriminación de género que actualmente predomina en el país? Mencione y explique al menos tres argumentos que permitan fundamentar su postura.

Fuente: Elaboración propia. 
Tabla 5. Evidencia histórica.

\begin{tabular}{|c|c|c|}
\hline $\begin{array}{l}\text { Aprendizaje de } \\
\text { segundo orden }\end{array}$ & Conceptualización & Evidencia \\
\hline \multirow{5}{*}{$\begin{array}{l}\text { Evidencia } \\
\text { histórica }\end{array}$} & \multirow{5}{*}{$\begin{array}{l}\text { Permite ir de un análisis } \\
\text { descriptivo de las fuentes a uno } \\
\text { heurístico y contextualizado de } \\
\text { éstas. Este concepto también } \\
\text { ayuda a evidenciar que la } \\
\text { historia es un conocimiento } \\
\text { hermenéutico, donde coexisten } \\
\text { diversas interpretaciones } \\
\text { historiográficas sobre un } \\
\text { determinado hecho. }\end{array}$} & $\begin{array}{l}\text { Evidencia consignada en el protocolo de la } \\
\text { actividad, técnica o estrategia }\end{array}$ \\
\hline & & $\begin{array}{l}\text { La evidencia histórica se pretende trabajar } \\
\text { en varios protocolos de estrategias } \\
\text { innovadoras y constructivistas, a } \\
\text { través de una indicación concreta que } \\
\text { solicita a los estudiantes desarrollar un } \\
\text { laboratorio histórico, y sus respectivas } \\
\text { cuatro heurísticas, para investigar sobre } \\
\text { una problemática específica. Destaca el } \\
\text { instructivo del juego de roles, diseñado } \\
\text { por el equipo 14, donde se señala dicho } \\
\text { principio (evidencia 4). }\end{array}$ \\
\hline & & $\begin{array}{l}\text { También cabe resaltar que los futuros } \\
\text { profesores sugieren, en diversos protocolos, } \\
\text { un listado de fuentes para orientar el trabajo } \\
\text { investigativo en cursos pertenecientes al } \\
\text { segundo ciclo de la Enseñanza Básica. Al } \\
\text { respecto, sobresale el instructivo del debate, } \\
\text { diseñado por el equipo 8, para discutir } \\
\text { sobre la prevalencia de la doctrina del } \\
\text { descubrimiento de Chile en el currículum } \\
\text { (evidencia 5). }\end{array}$ \\
\hline & & $\begin{array}{l}\text { Evidencia consignada en el instrumento de } \\
\text { evaluación }\end{array}$ \\
\hline & & $\begin{array}{l}\text { La mayor parte de los equipos de las } \\
\text { cátedras II y III elaboraron instrumentos que } \\
\text { buscan evaluar el laboratorio histórico, a } \\
\text { partir de la implementación sucesiva de las } \\
\text { cuatro heurísticas por parte del alumnado. } \\
\text { Destaca la dimensión evaluativa "laboratorio } \\
\text { de historia" de la rúbrica analítica, diseñada } \\
\text { por el equipo 14, para evaluar el juego de } \\
\text { roles (evidencia 6). }\end{array}$ \\
\hline
\end{tabular}

Evidencia 4 (Equipo 14)

3. Una vez asignado el personaje femenino de la Segunda Guerra Mundial, implemente un laboratorio histórico para investigar y delimitar el aspecto biográfico que deseen representar. Para ello, debe regirse por el principio de las cuatro heurísticas propuestas por Salazar y colaboradores (2017). A saber, estas son:

- Heurística de origen, teniendo en cuenta de dónde proviene el documento histórico y su propósito.

- Contextualización, con el fin de poner el documento en su contexto temporal y espacial.

- Lectura cerrada, para extraer la idea principal del documento.

- Corroboración heurística, para comparar las múltiples fuentes. 
Continuación Tabla 5

Evidencia 5 (Equipo 8)

2. Implemente un laboratorio histórico para elaborar los argumentos y los posibles contraargumentos que se presentarán en el debate. Se recomienda tomar como referencia las fuentes adjuntas por cada postura. Este listado sugerido debe ser ampliado por el equipo de trabajo.

Fuentes de la postura eurocéntrica

\section{Fuente 1}

Con perfecto derecho los españoles imperan sobre estos bárbaros del Nuevo Mundo e islas adyacentes, los cuales en prudencia, ingenio, virtud y humanidad son tan inferiores a los españoles como niños a los adultos y las mujeres a los varones, o los negros a los blancos, habiendo entre ellos tanta diferencia como la que va de gentes fieras y crueles a gentes clementísimas (Extracto del Tratado sobre las justas causas de la guerra contra los indios, Juan Ginés de Sepúlveda, 1550).

Fuentes de la postura contra-hegemónica

\section{Fuente 2}

"Que todos estáis en pecado mortal y en él vivís y morís, por la crueldad y tiranía que usáis con estas inocentes gentes. Decid, $[\ldots]$ ¿Con qué autoridad habéis hecho tan detestables guerras a estas gentes que estaban en sus tierras mansas y pacíficas, donde tan infinitas de ellas, con muerte y estragos nunca oídos, habéis consumido? ¿Cómo los tenéis tan opresos y fatigados, sin darles de comer ni curarlos en sus enfermedades, que de los excesivos trabajos que les dais incurren y se os mueren, y por mejor decir, los matáis, por sacar y adquirir oro cada día? ¿Y qué cuidado tenéis de quien los doctrine y conozcan a su Dios y criador, sean bautizados, oigan misa, guarden las fiestas y domingos? ¿Estos no son hombres? ¿No tienen ánimas racionales? ¿No sois obligados a amarlos como a vosotros mismos? ¿Esto no entendéis? ¿Esto no sentís?”. (Sermón del Fray Antonio de Montesinos, La Española, 1511).

\section{Fuente 3}

"Yo afirmo que yo mismo vi ante mis ojos a los españoles cortar manos, narices y orejas a los indios e indias, sin propósito, sino porque se les antojaba hacerlo, y en tantos lugares y partes que sería largo de contar". (Extracto de la Brevísima relación de la destrucción de las Indias, Bartolomé de las Casas, 1552).

\begin{tabular}{|c|c|c|c|c|}
\hline Criterio & $\begin{array}{l}\text { Experto } \\
\text { (4 puntos) }\end{array}$ & $\begin{array}{l}\text { Avanzado } \\
\text { (3 puntos) }\end{array}$ & $\begin{array}{l}\text { Intermedio } \\
\text { ( } 2 \text { puntos) }\end{array}$ & $\begin{array}{l}\text { Aprendiz } \\
\text { (1 punto) }\end{array}$ \\
\hline $\begin{array}{l}\text { Laboratorio de } \\
\text { historia }\end{array}$ & $\begin{array}{l}\text { En el laboratorio } \\
\text { histórico } \\
\text { implementado para } \\
\text { desarrollar el juego } \\
\text { de roles se observa } \\
\text { la aplicación de las } \\
\text { cuatro heurísticas } \\
\text { (heurística de origen, } \\
\text { contextualización, } \\
\text { lectura cerrada } \\
\text { y corroboración } \\
\text { heurística). }\end{array}$ & $\begin{array}{l}\text { En el laboratorio } \\
\text { histórico } \\
\text { implementado } \\
\text { para desarrollar el } \\
\text { juego de roles no se } \\
\text { observa la aplicación } \\
\text { de una de las } \\
\text { cuatro heurísticas } \\
\text { (heurística de origen, } \\
\text { contextualización, } \\
\text { lectura cerrada } \\
\text { y corroboración } \\
\text { heurística). }\end{array}$ & $\begin{array}{l}\text { En el laboratorio } \\
\text { histórico } \\
\text { implementado } \\
\text { para desarrollar el } \\
\text { juego de roles no se } \\
\text { observa la aplicación } \\
\text { de dos o tres de las } \\
\text { cuatro heurísticas } \\
\text { (heurística de origen, } \\
\text { contextualización, } \\
\text { lectura cerrada } \\
\text { y corroboración } \\
\text { heurística). }\end{array}$ & $\begin{array}{l}\text { En el laboratorio } \\
\text { histórico } \\
\text { implementado } \\
\text { para desarrollar el } \\
\text { juego de roles no se } \\
\text { observa la aplicación } \\
\text { de ninguna de las } \\
\text { cuatro heurísticas } \\
\text { (heurística de origen, } \\
\text { contextualización, } \\
\text { lectura cerrada } \\
\text { y corroboración } \\
\text { heurística). }\end{array}$ \\
\hline
\end{tabular}

Fuente: Elaboración propia. 
Tabla 6. Tiempo histórico.

\begin{tabular}{|c|c|c|}
\hline $\begin{array}{l}\text { Aprendizaje de } \\
\text { segundo orden }\end{array}$ & Conceptualización & Evidencia \\
\hline \multirow{4}{*}{ Tiempo histórico } & \multirow{4}{*}{$\begin{array}{l}\text { Promueve la aplicación de } \\
\text { conceptos temporales y } \\
\text { convenciones cronológicas } \\
\text { para analizar los cambios y las } \\
\text { continuidades de los procesos } \\
\text { históricos. }\end{array}$} & $\begin{array}{l}\text { Evidencia consignada en el protocolo de la actividad, } \\
\text { técnica o estrategia }\end{array}$ \\
\hline & & $\begin{array}{l}\text { Una parte importante de la muestra construyó } \\
\text { actividades de aprendizaje donde, a través de } \\
\text { preguntas abiertas, se busca incentivar a los alumnos a } \\
\text { evaluar los cambios y las continuidades de los hechos } \\
\text { o procesos históricos. Estas preguntas se engloban, } \\
\text { principalmente, en temáticas controversiales, tales } \\
\text { como la prevalencia de la doctrina del descubrimiento } \\
\text { de Chile en el currículum (evidencia 7) y la importancia } \\
\text { de la Guerra del Pacífico en la configuración territorial } \\
\text { actual (evidencia 8). }\end{array}$ \\
\hline & & Evidencia consignada en el instrumento de evaluación \\
\hline & & $\begin{array}{l}\text { Fue uno de los aprendizajes más complejos de } \\
\text { comprender por parte de los futuros docentes, ya } \\
\text { que tuvieron bastantes dificultades para definir } \\
\text { dimensiones o indicadores de evaluación en base } \\
\text { al tiempo histórico. Uno de los trabajos mejor } \\
\text { logrados se observa en una de las dimensiones } \\
\text { evaluativas presentes en la lista de cotejo, elaborada } \\
\text { por los integrantes del equipo 15, para calificar } \\
\text { una exposición oral sobre la Dictadura militar, la } \\
\text { transición política y los desafíos de la democracia } \\
\text { actual (evidencia 9). }\end{array}$ \\
\hline
\end{tabular}

Evidencia 7 (Equipo 8): Explique los cambios económicos, políticos y sociales que produjo la llegada de Diego de Almagro y de Pedro de Valdivia en Chile.

Evidencia 8 (Equipo 11): Compare y analice los cambios territoriales producidos en Bolivia, Chile y Perú tras el desenlace de la Guerra del Pacífico (1879-1884).

\begin{tabular}{|c|c|c|c|c|}
\hline \multicolumn{5}{|c|}{ Evidencia 9 (Equipo 15) } \\
\hline $\begin{array}{l}\text { Aprendizaje de } \\
\text { segundo orden }\end{array}$ & Concepto & Indicador & $\begin{array}{l}\text { Logrado } \\
\text { (1 punto) }\end{array}$ & $\begin{array}{l}\text { No logrado } \\
\text { (0 puntos) }\end{array}$ \\
\hline \multirow[t]{2}{*}{ Tiempo histórico } & $\begin{array}{l}\text { Uso de convenciones temporales } \\
\text { (conjunto de términos, estándares } \\
\text { o criterios que permiten delimitar } \\
\text { marcos temporales flexibles o } \\
\text { fijos, tales como el concepto } \\
\text { de generación, milenio, siglo, } \\
\text { decenio, año, etc.). }\end{array}$ & $\begin{array}{l}\text { Identifican el } \\
\text { período de vigencia } \\
\text { de la Dictadura } \\
\text { Militar de Augusto } \\
\text { Pinochet. }\end{array}$ & & \\
\hline & $\begin{array}{l}\text { Auge y decadencia (se refieren } \\
\text { a los períodos de despegue, } \\
\text { estabilidad, crisis y decadencia } \\
\text { que tienen todas las sociedades). }\end{array}$ & $\begin{array}{l}\text { Evalúan el colapso } \\
\text { del modelo ISI, } \\
\text { tras el quiebre } \\
\text { institucional } \\
\text { producido en } 1973 .\end{array}$ & & \\
\hline
\end{tabular}




\begin{tabular}{|c|c|c|}
\hline \multirow{3}{*}{ Tiempo histórico } & $\begin{array}{l}\text { Diacronía (Evolución de un hecho } \\
\text { histórico a través del tiempo). }\end{array}$ & $\begin{array}{l}\text { Analizan, en } \\
\text { perspectiva } \\
\text { histórica, la crisis } \\
\text { del modelo ISI } \\
\text { como un factor } \\
\text { desencadenante del } \\
\text { golpe de Estado de } \\
1973 .\end{array}$ \\
\hline & $\begin{array}{l}\text { Sincronía (Coincidencia en el } \\
\text { tiempo de dos o más hechos } \\
\text { históricos, especialmente cuando } \\
\text { el desarrollo de uno es vinculante } \\
\text { a la evolución de otro). }\end{array}$ & $\begin{array}{l}\text { Relacionan el golpe } \\
\text { de Estado de } 1973 \\
\text { con el contexto de } \\
\text { Guerra Fría. }\end{array}$ \\
\hline & $\begin{array}{l}\text { Cambio y continuidad } \\
\text { (transformaciones, matices y } \\
\text { continuidades que se registran } \\
\text { en un determinado período de } \\
\text { tiempo). }\end{array}$ & $\begin{array}{l}\text { Analizan la } \\
\text { transición } \\
\text { económica, política } \\
\text { y social producida } \\
\text { desde el Estado de } \\
\text { bienestar hacia el } \\
\text { Estado subsidiario } \\
\text { durante el período } \\
\text { 1975-1985. }\end{array}$ \\
\hline
\end{tabular}

Fuente: Elaboración propia.

Tabla 7. Causas y consecuencias.

\begin{tabular}{|c|c|c|}
\hline $\begin{array}{l}\text { Aprendizaje de } \\
\text { segundo orden }\end{array}$ & Conceptualización & Evidencia \\
\hline & & $\begin{array}{l}\text { Evidencia consignada en el protocolo de la actividad, } \\
\text { técnica o estrategia }\end{array}$ \\
\hline & Promueve el análisi & $\begin{array}{l}\text { Este aprendizaje fue el más utilizado en los protocolos } \\
\text { de las actividades diseñadas, ya que una parte } \\
\text { importante de éstas incluye preguntas y ejercicios } \\
\text { prácticos de indagación relacionados con las causas } \\
\text { y consecuencias de los hechos históricos. Entre los } \\
\text { principales temas trabajados, se encuentran la Guerra } \\
\text { del Pacífico (evidencia 10), la Ocupación de la Araucanía } \\
\text { (evidencia 11) y el Estallido Social (evidencia 12). }\end{array}$ \\
\hline
\end{tabular}

Causas y consecuencias causas y las consecuencias de los procesos históricos.
Evidencia consignada en el instrumento de evaluación

Fue uno de los aprendizajes más sencillos de comprender por parte de los alumnos, ya que no tuvieron dificultades para definir dimensiones o indicadores de evaluación en base a las causas y consecuencias de los procesos históricos. Uno de los trabajos mejor logrados se observa en una de las dimensiones evaluativas presentes en la lista de cotejo, elaborada por los integrantes del equipo 6, para calificar una exposición oral sobre el Estallido Social (evidencia 13). 


\section{Continuación Tabla 7}

Evidencia 10 (Equipo 11): Explique las repercusiones de la Guerra del Pacífico (1879-1884) para la economía chilena de finales del siglo XIX y comienzos del siglo XX.

Evidencia 11 (Equipo 12): Analice las consecuencias políticas, económicas y sociales de la Ocupación de la Araucanía para el pueblo mapuche y el Estado chileno.

Evidencia 12 (Equipo 6): Explique las causas que gatillaron el Estallido Social en Chile.

\begin{tabular}{|c|c|c|c|}
\hline \multicolumn{4}{|l|}{ Evidencia 13 (Equipo 6) } \\
\hline Aprendizaje de segundo orden & Indicadores & $\begin{array}{l}\text { Logrado } \\
\text { (1 punto) }\end{array}$ & $\begin{array}{l}\text { No } \\
\text { logrado } \\
(0 \text { puntos })\end{array}$ \\
\hline \multirow{2}{*}{ Causas y consecuencias } & $\begin{array}{l}\text { Identifican y explican al menos tres causas } \\
\text { políticas, económicas o sociales del Estallido } \\
\text { Social }\end{array}$ & & \\
\hline & $\begin{array}{l}\text { Reconocen y analizan al menos tres } \\
\text { consecuencias del Estallido Social para la } \\
\text { sociedad chilena }\end{array}$ & & \\
\hline
\end{tabular}

Fuente: Elaboración propia.

Tabla 8. Empatía histórica.

\begin{tabular}{|c|c|c|}
\hline $\begin{array}{l}\text { Aprendizaje de } \\
\text { segundo orden }\end{array}$ & Conceptualización & Evidencia \\
\hline \multirow{4}{*}{ Empatía histórica } & \multirow{4}{*}{$\begin{array}{l}\text { Fomenta la comprensión } \\
\text { contextualizada de los hechos } \\
\text { del pasado, para evitar la } \\
\text { emisión de juicios infundados } \\
\text { sobre éstos. }\end{array}$} & $\begin{array}{l}\text { Evidencia consignada en el protocolo de la actividad, } \\
\text { técnica o estrategia }\end{array}$ \\
\hline & & $\begin{array}{l}\text { La empatía histórica es ampliamente utilizada en } \\
\text { los protocolos a través de situaciones hipotéticas, } \\
\text { que invitan al alumnado a ponerse en el "lugar" de } \\
\text { un determinado rol o personaje histórico, para que, } \\
\text { desde esa posición, pueda comprender su forma de } \\
\text { actuar y su respectivo contexto histórico. Resalta la } \\
\text { actividad elaborada por el equipo } 15 \text { (evidencia 14) y el } \\
\text { instructivo del juego de roles, diseñado por el equipo } \\
\text { 14, donde se precisa una serie de indicaciones para que } \\
\text { los alumnos y alumnas puedan interpretar a una mujer } \\
\text { destacada de la Segunda Guerra Mundial (evidencia 15). }\end{array}$ \\
\hline & & Evidencia consignada en el instrumento de evaluación \\
\hline & & $\begin{array}{l}\text { La mayor parte de los grupos de las cátedras II y III } \\
\text { elaboraron instrumentos que buscan evaluar la empatía } \\
\text { histórica en el estudiantado. Destaca la dimensión } \\
\text { evaluativa "vestuario y escenografía” de la rúbrica } \\
\text { analítica, diseñada por el equipo 14, para evaluar el } \\
\text { juego de roles (evidencia 16). }\end{array}$ \\
\hline
\end{tabular}

Evidencia 14 (Equipo 15)

Imagina que eres un periodista que vive en el contexto del golpe de Estado de 1973 y te han pedido que hagas un informe sobre el alcance de este hecho. Tu reporte sería... 
Continuación Tabla 8

Evidencia 15 (Equipo 14)

6. Cada equipo debe llevar el vestuario, utilería y escenografía que considere necesario para caracterizar a su personaje según el contexto histórico vivido por éste. Este material debe ser confeccionado por los propios estudiantes, ya que no se aceptará el arriendo o compra de éste. El objetivo de esta indicación es que puedan ser capaces de ponerse en el "lugar" del personaje a la hora de elaborar los insumos y, desde allí, tratar de entender el comportamiento y el entorno sociocultural del personaje a interpretar.

Evidencia 16 (Equipo 14)

\begin{tabular}{|c|c|c|c|c|}
\hline Criterio & $\begin{array}{l}\text { Experto } \\
\text { (4 puntos) }\end{array}$ & $\begin{array}{l}\text { Avanzado } \\
\text { (3 puntos) }\end{array}$ & $\begin{array}{l}\text { Intermedio } \\
\text { ( } 2 \text { puntos) }\end{array}$ & $\begin{array}{l}\text { Aprendiz } \\
\text { (1 punto) }\end{array}$ \\
\hline $\begin{array}{l}\text { Vestuario y } \\
\text { Escenografía }\end{array}$ & $\begin{array}{l}\text { El vestuario y } \\
\text { la escenografía } \\
\text { son congruentes } \\
\text { entre sí y se } \\
\text { enmarcan } \\
\text { totalmente } \\
\text { en la época } \\
\text { del personaje } \\
\text { histórico } \\
\text { representado. }\end{array}$ & $\begin{array}{l}\text { El vestuario y la } \\
\text { escenografía son } \\
\text { congruentes entre } \\
\text { sí, sin embargo, } \\
\text { presentan algunos } \\
\text { elementos que no } \\
\text { corresponden al } \\
\text { contexto histórico } \\
\text { del tema asignado. }\end{array}$ & $\begin{array}{l}\text { Existen varias } \\
\text { incongruencias } \\
\text { entre el vestuario } \\
\text { y la escenografía, } \\
\text { y muchos de sus } \\
\text { elementos no } \\
\text { concuerdan con } \\
\text { la época del tema } \\
\text { asignado. }\end{array}$ & $\begin{array}{l}\text { El vestuario y la } \\
\text { escenografía son } \\
\text { completamente } \\
\text { incongruentes entre } \\
\text { sí y están totalmente } \\
\text { descontextualizados } \\
\text { del tema asignado, } \\
\text { o bien no presentan } \\
\text { la indumentaria } \\
\text { básica requerida para } \\
\text { representar al personaje. }\end{array}$ \\
\hline
\end{tabular}

Fuente: Elaboración propia.

Tabla 9. Dimensión ética.

\begin{tabular}{lll}
\hline $\begin{array}{l}\text { Aprendizaje de } \\
\text { segundo orden }\end{array}$ & Conceptualización & Evidencia \\
\hline
\end{tabular}

Evidencia consignada en el protocolo de la actividad, técnica o estrategia

Este aprendizaje fue escasamente utilizado en los protocolos de las actividades diseñadas, ya que el profesorado en formación tuvo bastantes dificultades para comprender su importancia dentro de la formación del pensamiento histórico. Se intencionó, fundamentalmente, en

Permite evaluar responsabilidades y juzgar

Dimensión ética hechos controvertidos del pasado de forma contextualizada y fundamentada. actividades que incluyen preguntas relacionadas con la dimensión ética de hechos históricos controversiales, tales como el Estallido Social (evidencia 17) y el rol de la mujer en la historia chilena (evidencia 18).

Evidencia consignada en el instrumento de evaluación

Dado su nivel de complejidad, la dimensión ética, junto a la relevancia histórica, fueron los únicos conceptos que no se pudieron evidenciar en los instrumentos de evaluación diseñados por los futuros docentes. Se infiere que el nivel de profundidad y de análisis que se necesita para este aprendizaje genera un gran problema cognitivo para el estudiante, puesto que, pese al trabajo realizado, no se pudo verificar. 
Continuación Tabla 9

Evidencia 17 (Equipo 6): Explique por qué el sistema de AFP no ha sido capaz de entregar pensiones dignas a los adultos mayores del país. Para ello, considere que el 94\% de las mujeres y el $87,5 \%$ de los hombres jubilados en la modalidad de retiro programado reciben una pensión menor a \$154.304 (Fundación Sol, 2017).

Evidencia 18 (Equipo 13): Analice las motivaciones que tienen los productores de los textos escolares de Historia, Geografía y Ciencias Sociales para excluir total o parcialmente el rol de la mujer en la historia chilena.

Fuente: Elaboración propia.

Como se observa en el análisis de los e-portafolios, el profesorado en formación, en términos generales, fue capaz de aplicar los fundamentos epistémicos, pedagógicos y cognitivos de la asignatura de Historia para intencionar el diseño de actividades e instrumentos, que permitan fomentar y evaluar aprendizajes de segundo orden. No obstante, y tal como se constató, no se pudo visibilizar la construcción de evidencias evaluativas para los casos de la relevancia histórica y de la dimensión ética, ya que fueron conceptos sumamente complejos de comprender por parte de los futuros docentes. Algunas de las dificultades observadas fueron la falta de precisión epistemológica para definir dimensiones e indicadores de evaluación pertinentes a dichos aprendizajes, y la escasa comprensión de la dimensión ética de la historia como una habilidad primordial para realizar juicios éticos razonados y fundamentados sobre hechos controversiales o gloriosos del pasado.

También cabe destacar que gran parte de las evidencias adjuntas corresponde a los cursos (cátedra II y III) de los últimos cuatro semestres de la carrera. Esto no resulta para nada extraño, pues es lógico que los estudiantes que cuentan con un mayor avance curricular tengan una más alta probabilidad de pertenecer al segmento de la muestra que haya logrado mejores resultados al momento de planificar estrategias metodológicas y evaluativas para desarrollar el pensamiento histórico. Sin embargo, es importante mencionar que los equipos 9 y 10 de la cátedra II no pudieron finalizar de forma correcta el e-portafolio, porque los recursos presentados no respondieron eficazmente a las particularidades de la historia y su didáctica.

Otro aspecto clave a resaltar en el conjunto de recursos anexados por los alumnos y las alumnas en sus e-portafolios, es la gran cantidad de actividades o de estrategias metodológicas centradas en la recuperación de la memoria, en temáticas controversiales o en cuestiones socialmente vivas. Esto coincide con los hallazgos de Toledo y colaboradores (2015), quienes encontraron algunas referencias respecto a la conquista española y a la crisis del Estado de bienestar en Chile. La importancia dada a dichos temas constituye un hallazgo relevante y significativo, ya que es altamente pertinente con el contexto sociopolítico y de pandemia que atraviesa el país, donde el gran propósito de la enseñanza de la historia es desarrollar aprendizajes significativos y actualizados en los alumnos y alumnas para formar ciudadanos(as) comprometidos con el bien común y la solidaridad universal.

Asimismo, vale la pena mencionar que la reflexión pedagógica realizada por los y las estudiantes destaca la importancia de construir instrumentos pertinentes para evaluar los aprendizajes de segundo orden. Al respecto, argumentan que no tiene ningún sentido 
desarrollar actividades o estrategias que tengan como objetivo la promoción de tales competencias, sino se cuenta con instrumentos evaluativos efectivos, que permitan recoger información fidedigna sobre el desempeño del alumnado y tomar decisiones de mejora que contribuyan a guiar su proceso de aprendizaje.

Con la finalidad de desarrollar el conocimiento pedagógico y disciplinar suficiente para que los futuros profesores sean capaces de elaborar recursos atingentes a la especialidad, resulta imprescindible que el académico formador sea un profesional altamente competente para convertir una parte de las actividades didácticas en un proceso de aprendizaje por descubrimiento, donde el estudiante en vez de recibir los contenidos de forma pasiva, pueda descubrir los conceptos y sus relaciones para integrarlos a su esquema cognitivo (Tarr, 2018). Por tal motivo, al momento de implementar este tipo de experiencia en asignaturas de historia y su didáctica, es de vital importancia responder a sus especificidades epistemológicas, pedagógicas y cognitivas, porque con las estrategias didácticas y evaluativas diseñadas para esta clase en particular no se busca analizar la capacidad de los alumnos y las alumnas para retener datos elementales de personajes o efemérides, sino que se pretende promover y evaluar el desarrollo del pensamiento histórico.

Para adoptar este principio, es necesario que los profesores de la especialidad posean conocimientos sólidos y actualizados sobre la disciplina histórica y su enseñabilidad, ya que, en caso contrario, siguiendo a Vásquez (2016), se corre el riesgo de que el cuerpo docente desarrolle una visión parcelada y tradicional de la historia en la sala de clases. Se está plenamente consciente de este gran desafío, por lo que, desde la perspectiva del académico formador, requerirá, por una parte, un mayor esfuerzo para trabajar de forma más frecuente en experiencias similares, donde el profesorado en formación pueda potenciar sus aprendizajes para diseñar actividades e instrumentos evaluativos, que consignen la promoción y evaluación de competencias históricas; y por otra, resulta fundamental impulsar la creación de equipos docentes que tengan la misión de planificar propuestas de innovación como la presente.

\section{CONCLUSIÓN}

Existen múltiples inconvenientes que impactan negativamente en la formación de docentes de historia, tales como la falta de asignaturas o temáticas relacionadas con el uso pedagógico de las TIC en la enseñanza de la especialidad, y el predominio del conocimiento disciplinar por sobre el saber didáctico; no obstante, uno de los problemas más preocupantes es la escasa preparación que reciben los profesores en formación para promover y evaluar el pensamiento histórico en sus futuros estudiantes. Al respecto, cabe destacar que el actual contexto de pandemia de Covid-19 exige al académico formador utilizar instrumentos de evaluación online y repensar sus estrategias formativas, para ayudar a sus alumnos y alumnas a reflexionar sobre la necesidad de diseñar propuestas y recursos pedagógicos atingentes al desarrollo de competencias históricas.

Tal como se demostró en esta investigación, el e-portafolio o portafolio electrónico es un instrumento evaluativo muy efectivo para cumplir con dicha finalidad. Esto se debe a que resultó ser una pieza relevante y pertinente para promover la planificación de propuestas, 
que consideren los fundamentos epistémicos, pedagógicos y cognitivos propios de la clase de historia, para fomentar el pensamiento histórico en los futuros docentes, pues se observó un profundo desconocimiento inicial sobre esta materia.

Para el profesorado en formación, esta propuesta fue un espacio valioso para aprender a diseñar insumos adecuados para desarrollar aprendizajes de segundo orden. Para el docente, esta experiencia permitió reflexionar sobre la propia práctica pedagógica, ya que la investigación realizada aportó a la mejora de los aprendizajes pedagógicos y disciplinares de los participantes.

A pesar de sus ventajas, este estudio no está exento de limitaciones. La propuesta se realizó en una muestra pequeña, por lo que los resultados obtenidos dependieron principalmente de las características de los cursos seleccionados, y de la madurez de éstos para realizar las tareas asignadas; igualmente, obedecieron a las particularidades epistémicas, pedagógicas y cognitivas de la disciplina en que se inserta la propuesta, pues, como se evidenció, este factor es determinante al momento de planificar una actividad como la presente. Por lo tanto, no se garantizan los resultados de esta intervención para otros casos, ya que cada uno es único y presenta sus propias dificultades y potencialidades.

La investigación se presenta como un sustento teórico y empírico sólido para continuar desarrollando, especialmente en esta pandemia, nuevos estudios que contribuyan a mejorar los conocimientos del profesorado en formación sobre el diseño de estrategias didácticas y evaluativas pertinentes para promover y evaluar competencias históricas. Este principio cobra especial importancia porque constituye un pilar fundamental para dar coherencia, a través de dichos recursos, a las prácticas docentes que suelen aproximarse, de forma constructivista, en el aula.

Sin embargo, el aporte de esta investigación no sólo debe inspirar el diseño de actividades e instrumentos coherentes a la enseñanza de la disciplina, sino que también debe posibilitar la implementación de experiencias, a partir del uso de tales insumos, para evaluar su efectividad en contextos reales de aula. Una buena opción para cumplir este objetivo es el desarrollo de semilleros de investigación en la escuela, donde los futuros profesores, bajo la supervisión del académico formador, tengan la posibilidad de aplicar los protocolos diseñados en la clase y de reflexionar sobre esta experiencia de inmersión pedagógica.

\section{AGRADECIMIENTOS}

Esta investigación se enmarca en el Proyecto FAD 13/2019: "El debate y el juego de roles como metodologías activas en la enseñanza de la Historia. Una experiencia en Educación Superior", adscrito a la Universidad Católica de la Santísima Concepción, Chile. Se agradece a la institución patrocinante por el apoyo otorgado.

\section{REFERENCIAS}

Álvarez, H. (2020a). El uso del debate en la Educación en Derechos Humanos. Problemas, desafíos y potencialidades. Mendive, 18(2), 219-234. 
Álvarez, H. (2020b). Enseñanza de la historia en el siglo XXI: Propuestas para promover el pensamiento histórico. Revista de Ciencias Sociales, 26(Especial 2), 442-459.

Arancibia, M., Halal, C., \& Romero, R. (2017). Valoración y barreras en la integración del e-portafolio en el proceso de práctica inicial por parte de docentes y estudiantes de Educación Superior. Pixel-Bit. Revista de Medios y Educación, 51, 151-163.

Barbour, R. (2013). Los grupos de discusión en investigación cualitativa. Madrid: Editorial Morata.

Berlanga, M., \& Juárez, L. (2020). Paradigmas de evaluación: Del tradicional al socioformativo. Diálogos sobre Educación, 11(21), 1-14.

Bozu, Z. (2012). El portafolio docente como estrategia formativa innovadora del profesorado novel universitario: Caso de estudios. Revista de Educación, 358(1), 238-257.

Cabero, J., López, E., \& Llorente, M. (2012). E-portafolio universitario como instrumento didáctico 2.0 para la reflexión, evaluación e investigación de la práctica educativa en el Espacio Europeo de Educación Superior. Virtualidad, Ciencia y Educación, 3(4), 27-46.

Chávez, P. (2016). El portafolio digital como instrumento de reflexión y autoevaluación docente en la educación superior. Revista Aletheia, 9(1), 76-97.

Cisterna, F. (2005). Categorización y triangulación como procesos de validación del conocimiento en investigación cualitativa. Theoria, 14(1), 61-71.

Coller, X. (2005). Estudio de casos. Madrid: Centro de Investigaciones Sociológicas.

Denzin, N., \& Lincoln, I. (2012). El campo de la investigación cualitativa. Manual de investigación cualitativa. Barcelona: Gedisa.

Díaz, F., Romero, E., \& Heredia, A. (2011). El portafolio electrónico como herramienta de reflexión sobre el desarrollo profesional y la formación en estudiantes de posgrado. Revista Observar, 5, 7-20.

Díaz, F., Romero, E., \& Heredia, A. (2012). Diseño tecnopedagógico de portafolios electrónicos de aprendizaje: Una experiencia con estudiantes universitarios. Revista Electrónica de Investigación Educativa, 14(2), 103-117.

Domingo, A., \& Gómez, M. (2014). La práctica reflexiva: Bases, modelos e instrumentos. Madrid: Ediciones Narcea.

Flick, U. (2014). La gestión de la calidad de la investigación cualitativa. Madrid: Editorial Morata.

Garcés, V. (2020). Alfabetizar en convivencia y ciudadanía. Una revisión documental de la educación ciudadana para la resolución de la violencia y el conflicto sociocultural. Sophia, 16(1), 4-18. https://doi.org/10.18634/sophiaj.16v.1i.874

Fundación Sol. (2017). Porcentaje de jubilados con pensiones menores a \$154.304, por sexo. Santiago de Chile: Fundación Sol. Recuperado de https://fundacionsol.cl/blog/ graficos-3/post/porcentaje-de-jubilados-con-pensiones-menores-a-154-304-porsexo-6254

García, F., Corell, A., Abella, V., \& Grande, M. (2020). La evaluación online en la educación superior en tiempos de la COVID-19. Education in the Knowledge Society, 21, 1-26. https://doi.org/10.14201/eks.23086

Gómez, G., \& Miralles, P. (2015). ¿Pensar históricamente o memorizar el pasado? La evaluación 
de los contenidos históricos en la educación obligatoria en España. Revista de Estudios Sociales, 52, 52-68.

Gómez, C., Miralles, P., \& Chapman, A. (2017). Los procedimientos de evaluación en la clase de Historia. Un análisis comparativo a través de las opiniones de los docentes en formación en España e Inglaterra. Revista Electrónica Interuniversitaria de Formación del Profesorado, 20(2), 45-61.

Gómez, C., Rodríguez, R., \& Mirete, A. (2018). Percepción de la enseñanza de la historia y concepciones epistemológicas. Una investigación con futuros maestros. Revista Complutense de Educación, 29(1), 237-250.

González, B., \& Fàbregues, S. (2019). La práctica de la investigación cualitativa en ciencias sociales y de la educación. Barcelona: Editorial UOC.

González, A., Santisteban, A., \& Pagès, J. (2020). Finalidades de la enseñanza de la historia en futuros profesores. Magis. Revista Internacional de Investigación en Educación, 13, 1-23. http://doi.org/10.11144/Javeriana.m13.fehf

Guba, E., \& Lincoln, Y. (2012). Controversias paradigmáticas, contradicciones y confluencias emergentes. En N. Denzin \& I. Lincoln (Coords.), El campo de la investigación cualitativa. Manual de investigación cualitativa (pp. 38-78). Barcelona: Gedisa.

Gudín, E., \& Chávarri, S. (2019). Fotografía en el aula para el desarrollo del pensamiento histórico. Didáctica de las Ciencias Experimentales y Sociales, 37, 19-36.

Habib, H., González, C., Collazos, C., \& Yousef, M. (2020). Estudio exploratorio en Iberoamérica sobre procesos de enseñanza-aprendizaje y propuesta de evaluación en tiempos de pandemia. Education in the Knowledge Society, 21, 1-9.

Hine, C. (2011). Etnografía virtual. Barcelona: Editorial UOC.

López, M. (2020). Concepciones y prácticas de profesores de Historia sobre la construcción didáctica del tiempo histórico mediado por el uso de las TIC. Cuaderno de Pedagogía Universitaria, 17, 29-43. https://doi.org/10.29197/cpu.v17i33.372

Machado, M., Alanis, I., \& Ruiz, E. (2017). La tecnología como inclusión educativa de la diversidad cultural: Transformando prácticas informales de educación en los Estados Unidos. Pedagogía Social. Revista Interuniversitaria, 29, 55-66.

Marolla, J., \& Saavedra, C. (2020). Presencia y ausencia de América Latina. La didáctica de las ciencias sociales y la interculturalidad como desafío para la enseñanza. Revista Interdisciplinaria de Estudios Latinoamericanos, 4(1) 75-92.

Moral, C. (2006). Criterios de validez en la investigación cualitativa actual. Revista de Investigación Educativa, 24(1), 147-164.

Moreno, P., López, F., \& Cruz, M. (2014). Portafolio digital: Un nuevo formato de aprendizaje. Didáctica de las Ciencias Experimentales y Sociales, 28, 83-94. https://doi.org/10.7203/ dces.28.3182

Palacios, N., Chaves, L., \& Martin, W. (2020). Desarrollo del pensamiento histórico. Análisis de exámenes de los estudiantes. Magis. Revista Internacional de Investigación en Educación, 13, 1-29. http://doi.org/10.11144/Javeriana.m13.dpha

Ponce, O. (2013). Investigación cualitativa en educación: Teorías, prácticas y debates. San Juan: Publicaciones Puertorriqueñas. 
Prats, J. (2011). Didáctica de la Geografía y la Historia. Barcelona: Editorial Graó.

Rubio, M., \& Galván, C. (2013). Portafolios digitales para el desarrollo de competencias transversales. Aportaciones principales de los estudios con Carpeta Digital en el marco del Grupo de Investigación Ensenyament i Aprenentatge Virtual. Digital Education Review, 24, 53-68.

Rué, J. (2016). Entornos de aprendizaje digitales y calidad de la educación superior. Barcelona: Oberta UOC Publishing.

Sáiz, J., \& Domínguez, J. (2017). Aprender sobre la historia: Competencias metodológicas en educación secundaria. En C. Gómez, R. López, P. Miralles y J. Prats (Eds.), Enseñanza de la historia y competencias educativas (pp. 23-47). Barcelona: Editorial Graó.

Salazar, R., Orellana, C., Muñoz, C., \& Bellati, I. (2017). El aula como laboratorio histórico: La Guerra Civil Española. En C. Gómez, R. López, P. Miralles y J. Prats (Eds.), Enseñanza de la historia y competencias educativas (pp. 110-126). Barcelona: Editorial Graó.

Seixas, P., \& Morton, T. (2012). The big six historical thinking concepts. Toronto: Nelson.

Simons, H. (2011). Estudio de caso: Teoría y práctica. Madrid: Editorial Morata.

Soledispa, C., Arce, A., Zuña, E., \& Ramos, J. (2020). El portafolio electrónico del docente universitario como una evidencia de su labor educativa. Journal of Business and Entrepreneurial Studies, 4(1), 1-12.

Soria, V., \& Carrió, M. (2016). Pedagogías disruptivas para la formación inicial del profesorado: Usando blogs como e-portafolio. Profesorado. Revista de Currículum y Formación de Profesorado, 20(2), 382-398.

Suárez, Á. (2020). Comunidades proscritas. Una reflexión sobre las posibilidades de la etnografía virtual. Athenea Digital, 20(1), 1-15. https://doi.org/10.5565/rev/ athenea.2236

Tarr, R. (2018). A history teaching toolbox. Practical classroom strategies. London: CreateSpace Independent Publishing Platform.

Thorp, R., \& Persson, A. (2020). On historical thinking and the history educational challenge. Educational Philosophy and Theory, 1-12.

Toledo, I., Magendzo, A., Gutiérrez, V., \& Iglesias, R. (2015). Enseñanza de “temas controversiales" en la asignatura de historia y ciencias sociales desde la perspectiva de los profesores. Estudios Pedagógicos, 41(1), 275-292.

Valdés, M., \& Turra, O. (2017). Racionalidades curriculares en la formación del profesorado de Historia en Chile. Diálogo Andino, 53, 23-32. http://doi.org/10.4067/S071926812017000200023

Van Boxtel, C., Van Drie, J., \& Stoel, G. (2020). Improving teachers' proficiency in teaching historical thinking. In C. Berg \& T. Christou (Eds.), The palgrave handbook of history and social studies education (pp. 97-117). Springer International Publishing. https://doi. org/10.1007/978-3-030-37210-1_5

VanSledright, A. (2014). Assessing historical thinking and understanding. Innovation design for new standards. New York: Routledge.

Vásquez, G. (2016). Las bases curriculares 2013: Los desafíos actuales para la formación inicial y aprendizaje histórico de profesores de historia en Chile. Educar em Revista, 60, 
147-160. https://doi.org/10.1590/0104-4060.46005

Vega, M., \& Appelgren, D. (2019). E-portafolio: Una herramienta para el desarrollo de la práctica reflexiva de profesores en formación. Praxis, 15(1), 57-68. https://doi. org/10.21676/23897856.2983 